\title{
Espaços translacionais, a tradução em devir: reflexões desde Antoine Berman
}

Álvaro Faleiros*

Antoine Berman é, inegavelmente, um dos mais importantes pensadores da tradução da segunda metade do século XX no ocidente. Ainda que, como pertinentemente aponta Petry (2012), muitos de seus importantes escritos datem dos anos 1960 e 1970, para os fins deste artigo, utilizamos como marco seu primeiro grande ensaio, A prova do estrangeiro, publicado em $1984^{1}$. Nessa obra que o consagra no campo dos estudos da tradução, Berman apresenta, logo no início, uma carta de princípios intitulada "La traduction au manifeste", publicada primeiramente em 1981 na Argentina com o título "El lugar de la traduction". Trata-se de estudo redigido com o intuito de lançar as bases de uma disciplina autônoma capaz "de definir-se e situar-se por si mesma e, por conseguinte, ser comunicada, partilhada e ensinada" (BERMAN, 2002[1984], p.12).

A primeira tarefa enunciada para a constituição dessa disciplina consiste precisamente na elaboração de uma história da tradução (à qual se somam uma ética e uma analítica). Declara Berman (2002[1984], p.12): “A constituição de uma história da tradução é a primeira tarefa de uma teoria moderna da tradução". Fazer essa história implica "redescobrir pacientemente essa rede cultural infinitamente complexa e desconcertante na qual, em cada época, ou em espaços diferentes, ela se vê presa. E fazer do saber histórico assim obtido uma abertura de nosso presente" (BERMAN, 2002[1984], p.14).

\footnotetext{
* Universidade de São Paulo (USP).

${ }^{1}$ Citaremos a tradução de Maria Emília Pereira Chanut, publicada em 2002. Os itálicos e destaques, salvo indicação, são dos autores.
} 
No processo de elaboração dessa história, um dos fios da infinita e complexa trama cultural que chamou especialmente a atenção de Berman foi a historicidade da palavra traduction (tradução) e de sua distinção em relação a translation (translação). Na conclusão de $A$ prova do estrangeiro, ao discutir a interação entre a tradutologia, a linguística e a teoria da literatura, Berman (2002[1984], p. 327) afirma que "seu ponto de partida se baseia em algumas hipóteses fundamentais", e a primeira delas é que, "sendo um caso particular de comunicação interlinguística, intercultural e interliterária, a tradução é também o modelo de qualquer processo desse gênero" (Ibidem). O desejo de estudar a tradução como campo sui generis do saber leva-o ainda a destacar que, "de Novalis a George Steiner e Michel Serres, vimos edificarem-se teorias nas quais qualquer tipo de 'troca' (de 'translação') é interpretado como uma tradução" (Ibidem). Compreender as noções de tradução e de translação passa a ser uma questão relevante na construção do pensamento bermaniano. Tanto é que, alguns anos depois, além de várias referências ao tema em outros escritos, saem dois textos seus dedicados ao assunto: “Tradition-Translation-Traduction" (1988) e "De la translation à la traduction" (2011 [1988]), aos quais se soma um terceiro, póstumo, “Translatio studii et pouvoir royal" (1997)2. Neles, é reiterada “a necessidade de uma reflexão histórico-lexical sobre a tradução ou, mais precisamente, de uma arqueologia da tradução no espaço da cultura ocidental" (BERMAN, $\left.2011[1988]^{3}\right)$, p. 71).

\section{Tradição | translação}

O texto "Tradition-Translation-Traduction", visa levantar questões a respeito de três categorias - a tradução, a tradição e a translação - que, segundo o autor, desde 1984 ocupavam como temática seminários e estudos no Colégio Internacional de Filosofia. Ao afirmar que "interrogar-se sobre essas categorias significaria tentar esclarecê-las - e examinar suas conexões

\footnotetext{
${ }^{2}$ Esses três artigos estão na base do livro póstumo Jacques Amyot, traducteur français. Essai sur les origines de la traduction en France. Paris: Belin, 2012.

${ }^{3}$ Citamos neste artigo a excelente tradução brasileira de Marie-Helène Torres e Marlova Aseff.
} 
- a partir de sua historicidade, e não se ater a seu conteúdo conceitual atual"4, Berman (1988, p. 85) deixa claro seu projeto de evidenciar as relações entre as três categorias a partir de sua historicidade. E acrescenta que, ao tratar dessa historicidade, interessa compreender como essas categorias produzem questionamentos, sobretudo em relação à filosofia. Para tal, Berman parte da evidência de que a tradução, a tradição e a translação são palavras latinas. Se Roma é o berço do sentido ainda hoje atribuído às duas últimas: tradição e translação, o mesmo não vale para tradução.

Partindo das considerações de Hannah Arendt a respeito da autoridade e da tradição, Berman (1988, p. 86) observa que "A traditio é a transmissão de ações dos antepassados e dos costumes que as engendraram" 5 . Berman (1988, p. 87) recorre ao entendimento de Arendt de que o fato histórico capital é que os romanos pensaram precisar de pais fundadores. Os fundos herdados desses fundadores seriam, pois, transmitidos por meio da translatio. Trata-se de palavra cujo campo semântico é vasto como pode ser observado na definição do historiador Serge Lusignan (1986, p. 158-159):

\begin{abstract}
translatio pode significar em latim: o transporte físico de objetos, o deslocamento de pessoas, a transferência de direito ou de jurisdição, a transferência metafórica, o deslocamento de ideias e finalmente a tradução. A translatio pode designar tanto o deslocamento físico quanto a transferência simbólica, ele pode conotar tanto o transporte quanto a tomada de posse ${ }^{6}$.
\end{abstract}

Conforme Berman (1988, p. 87), a enumeração acima evidencia que a translatio abarca a quase totalidade dos sentidos de transferência e de transmissão. Trata-se de fenômeno fundamental na construção da própria cultura latina. "Roma torna-se assim uma cultura translativa na medida em que toma emprestado de outra cultura para 'aumentar', em determinadas

\footnotetext{
${ }^{4}$ «s'interroger sur ces catégories signifiera tenter de les éclairer - et d'examiner leurs connexions - à partir de leur historicité, et non s'en tenir à leur actuel contenu conceptuel ». Traduções nossas, salvo indicação.

5 «La traditio est la transmission des actions des ancêtres et des coutumes qu'ils ont engendrées »

${ }^{6}$ translatio peut signifier en latin : le transport physique d'objets, le déplacement de personnes, le transfert de droit ou de juridiction, le transfert métaphorique, le déplacement d'idées et finalement la traduction. La translatio peut désigner aussi bien le déplacement physique que le transfert symbolique, elle peut connoter le transport tout autant que la prise de possession.
} 
áreas (filosofia, poesia, arte), seus próprios recursos" (BERMAN, 1988, p. 87). A amplitude da concepção de translação faz com que esta abarque ainda a “operação tradutora".

Note-se que os romanos não têm um termo para tradução. Cícero, por exemplo, usa vertere, convertere, aliquid (latine) exprimere, ad verbum exprimere, (graece, latine) reddere, verbum pro verbo reddere... para se referir a ela. Ainda assim, delimita com clareza o lugar e o modo dessa operação, a saber, o espaço oratório da retórica e a transferência de sentido (BERMAN, 1988, p. 88). A definição desse espaço e modo não significa que sua definição não seja problemática, tanto é que a translação inclui também a imitação e a adaptação, não discernindo cada uma das operações translativas.

A intensa articulação entre translatio e traditio, fundante das culturas latinas, ganha novos contornos em meados do século XIV com o desenvolvimento dos translatio studii. Como aponta Berman (1988, p. 90), os translatio studii visam a transferência de saberes de uma cultura para outra. Esse processo é ao mesmo tempo topológico e linguístico. Berman lembra que, para boa parte dos autores medievais, o lugar de origem do saber é a Grécia; de lá migrou para Roma, estando apto para novas migrações pelas línguasculturas europeias modernas então em formação. Nasce dessa maneira o entendimento de que a história do ocidente é uma longa cadeia de translações, sendo esse seu destino.

Esse processo de transferência de saberes tem também uma importante dimensão linguística. Segundo Berman (1988, p. 91), para compreendê-la, é preciso primeiro lembrar que, durante a Idade Média, o latim não era uma língua de comunicação como é o inglês hoje. Tratava-se de uma língua de comunhão: comunhão de saberes entre os clérigos, comunhão do sagrado com os fiéis; não sendo preciso compreender a língua para "entrar em comunhão", diferentemente do que ocorre quando há comunicação. Berman também destaca que a rede linguística na qual operava o "'translator' medieval não era, portanto, idêntica à nossa" (BERMAN, 2011[1988], p. 79).

Com os translatio studii saímos da esfera da comunhão para a esfera da comunicação. É o momento em que as ditas "línguas vulgares", ainda que não estabilizadas, tornam-se médiums de translação e de comunicação. Par 
que isso ocorra, comenta Berman, as línguas modernas precisaram se "desnaturalizar" e se tornar "designações unívocas" sujeitas a regras lógicas. A essência da translação assim concebida é "a circulação através dos meios linguageiros normalizados de conteúdos universais e invariantes 7 " (BERMAN, 1988, p. 91). Nesse contexto, a "tradução" (ainda não nomeada como tal) seria uma dessas formas de circulação, compreendida como "puro movimento de transferência", uma vez que, o que se deve "transladar", nesse contexto, é a sentencia, ou seja, o sentido dos textos, devendo esse "sentido" ser "claro".

A busca de "clareza" faz com que a translatio seja de natureza "aumentativa". Conforme Berman (1988, p. 92), "na Idade Média, o aumento da translação tinha pelo menos três formas". Primeiramente, para que o texto fosse cler et entendable (claro e compreensível), o translador fazia vários acréscimos com o intuito de explicitar passagens supostamente ambíguas. Em segundo lugar, o translador reestruturava o original, segundo os princípios da ordinatio medieval, acrescentando, por exemplo, títulos e outras indicações de conteúdo. Por fim, o translador acrescentava glosas internas ou externas.

Procedimentos análogos, acrescenta Berman (1988, p. 93), ocorrem nas traduções modernas. Alguns deles são as notas de rodapé, o uso de itálicos, os prefácios, os posfácios e as edições bilíngues; o que não significa criticar esse aumento, mas "mostrar que todas essas 'ajudas à comunicação' fazem parte da tradução e lhe dão seu estatuto de translação" (p. 93). Não é uma informação menor reconhecer que, tanto na Idade Média quanto hoje em dia, a tradução pode ter certo estatuto de translação. Esse estatuto segue tendo importantes desdobramentos.

Em Pour une critique des traductions: John Donne, publicado em 1995, o crítico francês volta a tratar do assunto. Berman (1995, p. 18) enfatiza que “a tradução de uma obra faz parte de um conjunto mais amplo de translações ou de circulações". Esse processo, destaca ainda, pode se dar em sentidos opostos. De um lado, pode ir no sentido da comunicação (termo cunhado no século XIV por Nicole Oresme, um dos teóricos da translatio studii e

\footnotetext{
${ }^{7}$ la circulation à travers des médiums langagiers normalisés de contenus universels et invariants
} 
referência fundamental na origem da tradução francesa). De outro, no sentido da migração, ou, se preferirmos, da transformação, com a mutação e mestiçagem que implica. Um terceiro conjunto ainda é destacado por Berman - a tradicionalidade. A identificação dessas características leva Berman (Ibidem) a concluir que: "a tradução ocidental é tradicionalisante, translativa e aumentativa".

Em outro estudo, publicado postumamente, ainda a respeito dos translatio studii, Berman (1997, p. 196) afina ainda mais seu entendimento dos processos históricos aí implicados:

\begin{abstract}
Hoje em dia a translatio studii prossegue em escala mundial. O saber ocidental transferido nas duas Américas, na China, no Japão etc, passa e seguirá passando por profundas mutações. A visão de um saber ocidental "universal" que imporia seus esquemas e suas leis a todas as outras culturas do globo negligencia o fato de que, mesmo não havendo necessariamente "resistência", toda transferência de saberes para outra área linguística, cultural, histórica leva ipso facto à sua mutação. $\mathrm{O}$ pensamento psicanalítico, para usar um exemplo bem atual, traduzido em francês, inglês, espanhol, árabe etc adquire, em cada tradução outra fisionomia. A cada vez, todo o aparelho linguageiro e conceitual é modificado. Isso significa que passar de uma língua a outra, para um determinado saber, nunca é uma transferência neutra de "conteúdos", mas uma verdadeira reviravolta ${ }^{8}$.
\end{abstract}

A síntese acima corrobora o entendimento de Sherry Simon (2001, p. 24), quando afirma que, para Berman, a noção de translation é essencial para o desenvolvimento dessa consciência histórica, "uma vez que Berman quer mostrar que cada ato de tradução está posto num envelope de níveis interpretativos, num feixe de obrigações e de liberdades, uma mediação que comporta simultaneamente determinantes conceituais, estéticos e políticos". Não se trata, pois, de um conceito menor para o pensamento bermaniano.

\footnotetext{
${ }^{8}$ De nos jours, la translatio studii se poursuit à l'échelle mondiale. Le savoir occidental, transféré dans les deux Amériques, en Chine, au Japon, etc., y subit et y subira encore de profondes mutations. La vision d'un savoir occidental «universel» qui imposerait ses schémas et ses lois à toutes les autres cultures du globe néglige le fait, non que ces cultures lui «résisteraient», mais que tout transfert d'un savoir dans une autre aire langagière, culturelle, historique amène ipso facto sa mutation. La pensée psychanalytique, pour prendre un exemple fort actuel, traduite en français, en anglais, en espagnol, en japonais, en arabe, etc., y prend à chaque fois une autre physionomie. À chaque fois, c'est tout l'appareil langagier et conceptuel de la psychanalyse qui se trouve modifié. Cela signifie que passer d'une langue à une autre, pour un savoir, n'est jamais un transfert neutre de «contenus», mais un véritable bouleversement.
} 
Conforme Simon, seria essa noção de translation que daria conta da interação entre a tradução e o meio literário; sendo ela uma espécie de "teoria geral da passagem de uma obra de uma 'língua-cultura' para outra"

Essa teoria geral, contudo, talvez até pelo fascínio de sua abrangência, muitas vezes se confunde com o próprio ato de traduzir. Berman (2009[1989]) está atento a esse risco, identificando como uma das onze tarefas da tradutologia "explorar" o que chama de "fronteiras da tradução". Certo, a área da tradução toca outras áreas do conhecimento, como a leitura, as transferências culturais, literárias, artísticas, científicas, e não raro nesse espaço sucumbe-se à "tentação de construir uma teoria 'generalista da tradução' que englobaria a 'tradução restrita' e os outros modos de 'translação'. Sucumbiram a essa tentação o Romantismo alemão, Steiner, Serres...". (BERMAN, 2009[1989], p. 350). A tarefa da tradutologia, nesse contexto, não é menor consistindo, conclui Berman, "sobretudo, em articular todas essas áreas de transformação, sem confundi-las".

\section{Translação | tradução}

Como lembra Berman (1988, p. 94), traducere e traductio não significavam na Roma antiga o que se chama hoje de "tradução". Traductor em Cícero, é aquele que faz a passagem da ordem dos patrícios para a ordem dos plebeus. Em “Da translação à tradução", Berman (2011 [1988], p. 82) explora mais o tema ao destacar: “o verbo traduire já existia na França no século XV, mas somente no domínio jurídico, onde se mantém até hoje, como quando dizemos: "Il a été traduit en justice" [Ele foi conduzido aos tribunais]". Até o final do século XVI, tanto traducere quanto traduire guardam um sentido material, sem relação com o que se convencionou modernamente chamar "tradução".

\footnotetext{
${ }^{9}$ Pour Berman... c'est la notion de « translation » qui rend compte de l'interaction entre la traduction et le milieu littéraire. La translation se veut une théorie générale du passage d'une œuvre d'une « langueculture » à une autre, la manière dont elle est révélée, signalée, intégrée dans un corpus d'enseignement, et le processus des traductions et retraductions, ainsi que la séquence des commentaires critiques qui l'entoure. [...] La notion de translation est essentielle à cette conscience historique, puisque Berman veut montrer que chaque acte de traduction est pris dans une enveloppe de niveaux interprétatifs, dans un faisceau de contraintes et de libertés, une médiation comprenant à la fois des déterminants conceptuels, esthétiques et politiques.
} 
Para compreender esse movimento, Berman (2011[1988], p. 72) observa que durante o Renascimento há um aumento massivo do volume de traduções, crescimento que só pode ser comparado ao que vivemos na segunda metade do século XX. Para Berman (Ibidem), “de uma forma mais profunda, esse crescimento corresponde ao que poderíamos chamar de uma ilimitação do campo da tradução". Se na Idade Média o corpus do que podia ser traduzido dependia da autoridade da igreja, no Renascimento, o campo do traduzível escancara-se e já não importa mais o texto, o gênero, a língua; tudo passa a ser digno de ser traduzido. Uma das consequências é que não apenas se começa a traduzir de tudo, mas surge a ambição confusa de "tudo" traduzir.

Essa inédita expansão modifica totalmente o estatuto da tradução que, apesar de sujeita a muitas críticas, adquire autoridade. A maioria dos pensadores do período põe-se a traduzir, fazendo do traduzido "origem e horizonte da escrita em língua materna" (p. 83). É nesse contexto que surge a acepção moderna de traduction. Como descreve Berman (p. 82):

\begin{abstract}
Foi Leonardo Bruni quem traduziu para o toscano tradotto o particípio passado traductum empregado por um autor latino, Aulo Gélio. Só que para esse último, traductum não significava "traduzido", mas "transportado". Na passagem em que emprega esse particípio passado, ele menciona a transferência de uma velha palavra grega ao latim, então, fala disso que chamamos de empréstimo. Ou seja, é, em princípio, o contrário de uma tradução.
\end{abstract}

Interessa sobretudo compreender como o "erro de tradução" de Bruni deu origem a um termo que, em pouco tempo, se impôs. A resposta, segundo Berman (1988, p. 94), provém da história medieval da palavra traductio.

Na Idade Média, o termo traductio aparece em escritos teológicos de inspiração aristotélica. Traductio não se refere aí à atividade tradutora mas sim a especulações sobre forma e matéria. Traductio, nesse contexto, distingue-se de informatio e de l'eductio. Conforme Berman (1988, p. 94), a informatio (in-formação) seria "a imposição de uma forma à uma matéria" e eductio seria "depreender uma forma existindo em potência de dentro de uma matéria". Quanto a ela, seria "a transferência ou transmissão de uma 
forma". O exemplo dado é tirado da Teodicéia de Leibniz. Nela o filósofo afirma que: "como se a alma das crianças fosse engendrada (per traducem) da alma ou das almas daqueles cujo corpo é engendrado (§ 86). Porque a alma é uma forma, a forma sendo, diz Leibniz, aquilo que é um princípio da ação, e se encontra naquele que age $(\S 87)^{10^{\prime \prime}}$. Daí depreende-se que, à época, a traductio seria a "a transmissão de uma forma, a forma sendo ela mesma o princípio ativo (agissant) de um ser" (BERMAN, 1988, p. 94) ${ }^{11}$.

Berman reconhece que Leonardo Bruni provavelmente inspirou Leibniz. Em seu tratado sobre Bruni (2006[1420], p. 61), ao refletir sobre atividade tradutora pondera:

Como aqueles que pintam um quadro segundo um modelo e reproduzem a figura, a postura, o modo de caminhar, a forma de todo o corpo, e não refletem sobre o que eles mesmo fariam, mas sobre o que o outro fez; do mesmo modo, na tradução, o bom tradutor se transformará com toda a mente, alma e determinação no autor primeiro do escrito e de algum modo o transformará tratando de expressar a forma, a postura e a textura do discurso, a cor e os diversos matizes. Disto se produz certamente efeito admirável.

A consciência aí expressa de que, como o pintor copista não copia apenas a figura, mas a postura, a forma de todo o corpo evidencia que, desde então, traduzir é engendrar uma forma a partir de outra forma: metamorfose. A conclusão de Berman (1988, p. 94) logo a seguir não poderia ser mais categórica: "A traductio é pois a transmissão ativa de uma forma, a forma sendo ela mesma o princípio ativo de um ser [...] A tradução moderna nasceu, e os românticos alemães não dirão nada diferente disso."12

Estamos diante de uma importante distinção na qual cabe à translatio medieval transferir sentido e à traductio moderna transferir a forma. Ambos trajetos implicam transformações, cujo alcance vincula-se ao modo como naquele gesto translacional ou tradutivo operam a tradição, a mutação e o aumento. Ao deslocamento de uma centralidade do sentido a uma

\footnotetext{
${ }^{10}$ comme si l'âme des enfants était engendrée (per traducem) de l'âme ou des âmes de ceux dont le corps est engendré (§ 86). Car l'âme est une forme, la forme étant, dit Leibniz, ce qui est un principe de l'action, et se trouve dans celui qui agit $(\S 87)$

11 transmission active d'une forme, la forme étant elle-même le principe agissant d'un être.

${ }^{12} \mathrm{La}$ traductio est donc la transmission active d'une forme, la forme étant elle-même le principe agissant d'un être [...] La traduction moderne est née, et les Romantiques allemands ne diront pas autre chose.
} 
centralidade da forma desde o Renascimento, soma-se a reflexão a respeito da morfologia de traductio.

O sufixo ductio interessa, como destaca Berman (1988), por sua alta produtividade no mundo moderno. Seguindo Yebra, o crítico francês observa que a ductio (ação de conduzir) não por acaso, está na origem de, pelo menos, dezenove vocábulos latinos. Seguindo seu curso pela traditio o sufixo é ainda mais produtivo nas línguas modernas europeias, formando outos 59 vocábulos em francês, 77 em espanhol, 79 em português, 88 em italiano e 117 em inglês. Dentro dessa família semântica, destacam-se como exemplos importantes termos como induction [indução], déduction [dedução], reduction [redução], séduction [sedução], production [produção] e reproduction [reprodução]. Sobre esses termos Berman retoma Michel Serres (1974, p. 9) para quem:

\footnotetext{
Somente conhecemos as coisas por meio dos sistemas de transformação dos conjuntos que os formam. Esses sistemas são no mínimo quatro. A dedução, na área lógico-matemática; a indução, no campo experimental; a produção, nos domínios da prática e a tradução, no âmbito dos textos. Não é completamente estranho que eles repitam a mesma palavra. (apud BERMAN 2011[1988], p.83)
}

Diferentemente da translação, que seria "um movimento de passagem mais anônimo", a tradução se caracterizaria por ser "uma atividade que tem um agente". Desse modo, todas as palavras formadas a partir de ductio suporiam “agentes" (BERMAN 2011[1988], p. 84).

A discussão em torno da "agência" certamente não é menor. Barbara Cassin (2004, p. 26), por exemplo, comenta em seu dicionário dos intraduzíveis que, agency em inglês, pode ser, em francês, "ação, agente, agência, agir". Destaca ainda que a palavra agency em inglês aparece no século XVIII, primeiramente com seu uso clássico aristotélico na oposição entre ação e paixão, agente e paciente. Agency designaria: a) a ação em sentido físico; b) aquilo que qualifica a ação em oposição à sujeição; c) aquilo que qualifica o agente em oposição ao paciente. E contemporaneamente, por seus usos em inglês, agency (em português normalmente traduzido por agência) permite 
pensar o agir não mais como categoria oposta à paixão, mas como “disposição" à ação - estar disposto a... desejos e afetos.

Nos estudos da tradução, agência (agency) também é um conceito produtivo. Tuija Kinnunen e Kaisa Koskinen, em 2010, publicam Translators' Agency, no qual tratam da questão. Para as autoras, a agência, um dos conceitos-chave nas ciências sociais modernas, tem sido conceitualizado de diferentes maneiras. No livro, é proposto por Kinnunen e Koskinen (2010, p. 6) o entendimento de agência como "disposição e habilidade de agir" (willingness and ability to act). Essa definição, construída coletivamente pelos participantes do evento que deu origem à obra, compreende, por um lado, a "disposição" (willingness) interna, individual; vinculando-se à consciência, intencionalidade e reflexividade com as questões éticas que envolve. Por outro lado, compreende a "habilidade" (ability); remetendo a instâncias mais coletivas de poder e de negociação, frequentemente assimétricas. A escolha depende do "estado" ou "posição" do tradutor no campo e diante da tradução. A definição de agência é, pois, individual e coletiva, ética e política. Haveria ainda uma tendência a compreender agência e estrutura como um par mutuamente dependente, no qual a agência "manteria" (maintains) a estrutura e a estrutura "restringiria" (constrains) a agência (p. 7). A agência assim pensada seria menos uma propriedade e mais "o efeito relacional de interações sociais". Seu real alcance é, pois, efetivamente dimensionado quando utilizado para um material específico em situado contexto.

Sherry Simon reconhece em Berman a adoção de postura situada, em contexto. Diferentemente de Toury, que se concentra nas "normas", Berman, já em La traduction et la lettre ou l'auberge du lointain (1985), não dissociaria a análise detalhada do entendimento global (SIMON, 2001, p. 23). A articulação entre essas diferentes instâncias pressupõe um entendimento do que configura o "lugar da tradução". Resta saber em que medida a agência concebida dessa maneira reverbera ou não nas análises de Berman.

\section{O lugar da tradução}

Este é o título do artigo de Berman publicado em 1981 na revista Sitio, em Buenos Aires que será posteriormente retomado como introdução a seu 
monumental A prova do estrangeiro. Como dissemos no início, trata-se de estudo elaborado com o intuito de fundamentar a tradução como prática autônoma, visando "estudiar el lugar que ocupa la traducción en un cierto campo cultural" (1981, p. 124) ${ }^{13}$. Além da primeira tarefa, que seria a "construcción de una história de la traducción", com especial interesse pelo modo como a prática da tradução se articula com a literatura, com as línguas e com as trocas culturais, outras duas tarefas se destacam: uma ética e uma analítica da tradução.

Ciente de que seu próprio discurso sobre a tradução é atravessado por questões ideológicas, históricas e culturais da França, Berman elabora uma ética pautada pelas questões que traduções "etnocêntricas" francesas colocam, e que, por sua vez, também são informadas pelo silenciamento diante do papel da tradução na história da literatura e da filosofia. Essa visada ética mais "positiva" de romper com o gueto ideológico em que se encontra a tradução supõe, para Berman, uma ética ${ }^{14}$ negativa, ou seja:

\begin{abstract}
una teoría de los valores ideológicos, culturales e literarios que tienden a desviar la traducción de su meta mas estricta. La teoria de la traducción noetnocéntrica es también una teoría de la traducción etnocéntrica es decir, de la mala traducción. Llamo mala traducción a la que, bajo la cobertura de la transmissibilidad, opera una negación sistemática de la extrangeridad de la obra extranjera. (p. 126)
\end{abstract}

A ela se soma a uma analítica. Conforme Berman (1981, p. 126); "el traductor debe 'someter a análisis', escrutar, observar los sistemas de deformación que amenazan su práctica, y que operan de manera inconsciente a nivel de sus elecciones lingüísticas y literarias".

No final do ensaio, Berman (p. 127) acrescenta à história, à ética e à analítica um quarto eixo: o da transtextualidade. Na primeira versão publicada, ao invés de "transtextualidade" encontra-se "intertextualidade". De todo modo, em ambos os textos, o desdobramento é praticamente o mesmo: "me parece verosímil suponer que la literatura se despliega siempre

\footnotetext{
${ }^{13}$ Optamos por usar neste tópico a versão em espanhol, a primeira deste texto fundador do pensamento bermaniano, em função do título, tão evocador.

${ }^{14}$ Para uma melhor compreensão da "ética bermaninana", seus alcance e limites, cf. Barbara Godard (2001).
} 
en el horizonte de la traducción". O horizonte da tradução e de seus estudos aí anunciado corresponde, em linhas gerais, a grande parte do projeto intelectual de Berman no que concerne a tradução.

Com efeito, é possível reconhecer no conjunto dos escritos bermanianos sobre a tradução e seu horizonte um desenvolvimento desses eixos. Em L'épreuve de l'étranger (1984) e posteriormente em Jacques Amyot traducteur français (1990-1991), o tema é a história das concepções alemã e francesa do traduzir. La traduction et la lettre ou l'auberge du lointain (1985), por sua vez, é o livro em que se apresenta a analítica negativa (da deformação), cabendo ao Pour une critique des traductions: John Donne (1995) o desenvolvimento de uma crítica, e a L'Age de la traduction - "La Tâche du traducteur" de Walter Benjamin, un commentaire, (2008), o desenvolvimento de um comentário.

"Critique, commentaire et traduction (Quelques réflexions à partir de Benjamin et de Blanchot)" é o título de uma artigo de Berman publicado em 1986 em que ele explica o desdobramento de uma analítica em crítica e comentário. Berman (1986, p. 88) inicia o ensaio perguntando-se se é possível analizar conjuntamente a crítica, o comentário e a tradução. Para isso, coloca primeiramente a relação entre os três nos seguintes termos:

\footnotetext{
Parece que a abordagem que os reúne fundamenta-se em homologias puramente formais: todos os três são "metatextos" cuja finalidade é "comunicar": crítica e comentário buscariam comunicar o "sentido" das obras, enquanto a tradução transmitiria o "sentido" em outras áreas linguísticas do que as suas. Desse parentesco de essência, surgiria a possibilidade de uma definição reversível: a tradução é crítica das obras (é o criticism by translation de Pound), crítica e comentário são, assim, atos de tradução. Este é o círculo que reúne no mesmo círculo os três metatextos, e que gira em torno do conceito de reformulação: toda reformulação é tradução, e vice-versa.

Há ainda outro ponto de vista que parece aproximá-los: toda obra é suscetível de uma infinidade de críticas, de comentários e de traduções. Sua proliferação não conheceria nenhum ponto final. O inacabamento é, pois, uma característica dos três metatextos.
} 
Todas essas considerações são em parte verdade. Quanto a mim, parto da seguinte proposição: comentário, crítica e tradução são três destinos das obras $^{15}$.

Não é difícil imaginar que, à semelhança de suas reflexões a respeito das relações entre "tradição, translação e comentário", Berman esteja interessado em diferenciar "crítica, comentário e tradução" para melhor articulá-los. Entre as distinções tratadas há, de um lado, comentário e tradução como práticas tradicionalizantes centradas na letra $\mathrm{e}$ consequentemente voltadas para a significância e o detalhe. De outro, a crítica como sendo essencialmente moderna e voltada para o sentido e o todo, operando não pelo estudo do detalhe e sim pelo uso da citação; fazendo com que esse tipo de crítica, em geral, desconsidere a tradução como espaço significante. Berman (1986, p. 89), contudo, não nega nenhum desses destinos. Pelo contrário, propõe-se a fazer uma "crítica da crítica fundamentada na explicitação da tradicionalidade do comentário e da tradução ${ }^{16 "}$.

Ainda que, para além da crítica, o autor francês, afirme que "tradução centrada na letra e tradução centrada no sentido se separem como dois possíveis do traduzir"17 (1986, p. 105), ele continua interessado em afirmar a especificidade da "tradução restrita" e sua proximidade com o comentário, como segue:

\footnotetext{
${ }^{15} \mathrm{Il}$ semblerait que l'approche qui les réunit soit fondée sur des homologies purement formelles : tous trois sont des «métatextes » dont la finalité est de "communiquer» : critique et commentaire chercheraient à communiquer le « sens » des œuvres, tandis que la traduction transmettrait ce «sens » dans d'autres aires langagières que les leurs. De cette parenté d'essence surgirait la possibilité d'une définition réversible : la traduction est critique des œuvres (c'est le criticism by translation de Pound), critique et commentaire sont, aussi bien, des actes de traduction. Tel est le cercle qui rassemble dans le même espace clos les trois métatextes, et qui tourne autour du concept de reformulation : toute reformulation est traduction, et vice-versa.

Il est encore un autre point de vue qui paraît les rapprocher : toute œuvre est susceptible d'une infinité de critiques, de commentaires et de traductions. Leur prolifération ne saurait connaître aucun point d'arrêt. L'inachèvement est donc une caractéristique des trois métatextes.

Toutes ces considérations possèdent leur part de vérité. Je partirai quant à moi de cette proposition : commentaire, critique et traduction sont trois destins des œuvres.

16 « critique » de la critique fondée sur l'explicitation de la traditionnalité du commentaire et de la traduction.

${ }^{17}$ traduction axée sur la lettre et traduction axée sur le sens se séparent comme les deux possibles du traduire.
} 
Primeiro, todo comentário de um texto estrangeiro é necessariamente tradução, como demonstra Heidegger. Não há (é um corolário) comentário de texto traduzido que se realiza sem referência ao original; pois nenhuma tradução, por mais literal que seja, preservaria o suficientemente a letra originária para que seu texto seja comentável. Mas o comentário de um texto estrangeiro só é tradução na medida em que traduz esse texto parte a parte, ao longo de sua progressão. Em si mesmo, ele não é apenas tradução: mais e menos de uma só vez. Entretanto, esse trabalho tradutivo abre caminho para a tradução propriamente dita: o comentário de Parmênides por Heidegger permite a tradução de Jean Beaufret. Enquanto a análise crítica cria obstáculos à tradução, o comentário o permite. Isso não é tudo: ele suplementa o que se pode chamar (retomando a expressão de Freud) o "defeito de tradução". Ou seja, onde para uma tradução (e toda tradução conhece um ponto de parada) começa o comentário. ${ }^{18}$

O crítico Berman (1986, p. 106), entretanto, não resume seu entendimento a essa distinção. Com o intuito de rearticular, após haver apontado para as diferenças, observa que "toda delimitação é violência" e que seu objetivo era apenas "marcar os limiares (bornes) do discurso crítico que, ainda hoje, demole a tradução e o comentário, para restituir a identidade dessas duas formas"19. O ponto aonde quer chegar Berman é o da reflexão, embasada na experiência do traduzir e do comentar.

\begin{abstract}
Para que essa reflexão possa prosperar, é necessário que a tradução se torne crítica e comentário de si mesma, não que ela viva como uma "prática" regida por uma "teoria". Nesse final de século, esses dois conceitos não são inocentes, pois só há "prática" no espaço tecnológico da modernidade. Ora a tradução é - e deve continuar sendo - um dos pilares da tradicionalidade; o que só é possível pela preservação de sua experiência numa reflexão. Com efeito, a "reflexão" é o conceito que une crítica, comentário e tradução. Tudo isso pouco importaria caso não se referisse a nossa relação
\end{abstract}

\footnotetext{
${ }^{18} \mathrm{D}^{\prime}$ abord, tout commentaire d'un texte étranger est nécessairement traduction, comme le montre Heidegger. Il n'est pas (c'est un corollaire) de commentaire d'un texte traduit qui s'accomplirait sans référence à l'original ; parce qu'aucune traduction, fût-ce la plus littérale, ne préserve assez la lettre originaire pour que son texte soit commentable. Mais le commentaire d'un texte étranger n'est traduction que dans la mesure où il ce texte partie par partie, au fur et à mesure de sa progression. En lui-même, il n'est pas que traduction : plus et moins à la fois. Néanmoins, ce travail traductif ouvre la voie à la traduction proprement dite : le commentaire de Parménide par Heidegger permet la traduction de Jean Beaufret. Alors que l'analyse critique fait obstacle au traduire, le commentaire le permet. Ce n'est pas tout: il supplée à ce que l'on peut appeler (en reprenant une expression de Freud) le " défaut de traduction».

${ }^{19}$ Ce long parcours pourra sembler très « critique » pour la critique. Toute délimitation est violence : il s'agissait de marquer les bornes du discours critique, qui, aujourd'hui encore, écrase la traduction et le commentaire, et d'inaugurer une réflexion nous restituant l'identité de ces deux formes.
} 
às obras, e mais profundamente ainda da relação das obras com $o$ ser-nomundo ancorado na tradicionalidade ${ }^{20}$.

Voltamos à questão inicial em torno da tradição-translação-tradução, questão à qual, para compreendermos melhor o pensamento bermaniano, devemos voltar, mas agora sob outro ângulo: o da língua-cultura.

\section{A tradução do lugar: translation I traduction I Übersetzung}

Não raro Berman mobiliza em seus escritos os usos das palavras translation (em inglês), traduction (em francês) e Übersetzung (em alemão) para explicar o próprio modo como ele, um francês europeu conhecedor da América Latina, se situa no campo e como neste se situam suas próprias reflexões. Como já foi dito, não há travessia conceitual sem mutação e o cotejamento desses processos transformacionais em distintas culturas cria interessantes espaços de compreensão dos modos de constituição de determinados ethos. Nas palavras de Berman (2011[1988], p. 85) “a rede de linguagem na qual se insere sempre o conjunto dos termos designando o ato de traduzir em cada grande língua ocidental pode nos revelar como uma cultura pensa esse ato e determina ao mesmo tempo a sua natureza e o seu lugar".

Berman explora em alguns momentos esse esquema. Em "Da tradução à translação" (2011[1988]), por exemplo, inicia-se pela identificação no Webster's de quatro acepções de base para translation em inglês, a saber: 1) o ato de traduzir e o seu resultado; 2) o transporte material; 3) a transformação, ou transmutação, ou conversão; 4) a transferência de direitos. Em seguida, as compara às do dicionário Le Robert, que só fornece, em francês, duas acepções para traduction: 1) o ato de traduzir; 2) o seu resultado, a transposição. Note-se ainda que, segundo Berman (2011[1988], p. 84), "Eliminada por tradução, a palavra translação tem certa serventia [...] em francês, também, mas perdendo toda a ligação com a atividade tradutória".

\footnotetext{
${ }^{20}$ Pour que cette réflexion puisse s'épanouir, il faut que la traduction devienne critique et commentaire d'elle-même, non qu'elle se vive comme une "pratique " régie par une "théorie ». En cette fin de siècle, ces deux concepts ne sont pas innocents. Car il n'est de " pratique » que dans l'espace technologique de la modernité. Or la traduction est - et doit rester - l'un des piliers de la traditionnalité. Cela n'est possible qu'en préservant son expérience dans une réflexion. De fait, la « réflexion » est le concept qui unit critique, commentaire et traduction. Tout cela importerait peu s'il ne s'agissait de notre rapport aux œuvres, et plus profondément du rapport des œuvres à l'être-au-monde ancré dans la traditionnalité.
} 
Ao afinar a comparação, ele complementa: “O campo semântico de translation [translação] não é somente mais rico que o de traduction [tradução] e mais ligado à translatio latina: graças à polissemia desse termo, a língua inglesa pôde integrar a operação tradutória ao campo mais vasto das transformações" (BERMAN, 2011[1988], p. 85). Essa distinção o leva mais adiante a afirmar: "Mais precisamente, a língua inglesa não traduz, ela translata, isto é, ela faz circular os "conteúdos" que são de natureza translinguística" (p. 87).

A comparação é ampliada com a introdução daquela que parece ser a terceira e última "grande língua ocidental" - o alemão. Diferentemente das línguas anteriores, na língua alemã, a "tradução" seria uma "operação pela qual, num movimento duplo, algo estrangeiro é colocado além dele próprio [...], na língua traduzinte, e algo próprio é deportado, ou melhor, se deporta" (p. 88). A triangulação proposta permite a Berman (2011[1988], p. 89) concluir o seguinte a respeito da palavra francesa traduction:

\begin{abstract}
Mais delimitada (até limitada) que a translation e a Übersetzung, a tradução tem seu foco - conforme o que essa palavra fala na origem - na ação de traduzir: ora, essa ação, como todas compostas com ção, é por essência transformadora. Sem espanto daí, se a cultura francesa criou a forma de tradução mais "livre" da historia ocidental: a "bela infiel". Se a língua alemã concebe a "tradução" como um jogo recíproco do próprio e do estrangeiro, se a língua inglesa a concebe como uma circulação de significados fora de qualquer referência ao próximo ou ao estrangeiro, a língua francesa vê no ato de traduzir a aclimatação adaptadora do estrangeiro.
\end{abstract}

Apesar de citar apenas um dicionário de cada umas das três "grandes línguas ocidentais", Berman afirma de modo categórico a existência de diferentes índoles (identidades?) tradutórias em cada língua-cultura. Esse entendimento é retomado com algumas nuanças em Jacques Amyot, traducteur français. Essai sur les origines de la traduction en France (2012). O centro do argumento é que a tradução na França se origina com Jacques Amyot. Berman (2012, p. 19) esclarece que a origem não se confunde necessariamente com o início. A origem viria depois do início, quando alguma grande tradução viria definir os contornos de uma determinada figura do traduzir. 


\begin{abstract}
Essas "grandes traduções se tornam, para as traduções posteriores, referências obrigatórias. E se, nelas mesmas, elas não constituem obrigatoriamente "modelos", o modo como se realizaram torna-se um modelo que, como todo modelo, pode ser aceito, rejeitado, discutido, edulcorado, mas que segue inevitável. Uma vez fundada, a tradição-datradução rege todo ato tradutivo, estejam ou não os tradutores conscientes disso. Nesse sentido, a origem é absolutamente determinante. A grande tradução impõe sua autoridade e delimita o que é, num espaço cultural, o sentido e as formas concretas do traduzir (BERMAN, 2012, p. 19; tradução nossa).
\end{abstract}

No caso da França, segundo Berman (2012, p. 8), essa figura do traduzir tem como modelo latente a obra de Jacques Amyot, pois nela “a tradução já é adaptação livre, mas esse traço (que ele herda de seu século) é contrabalançado por uma escrupulosa fidelidade filológica". Há, pois, uma dupla origem contida em Amyot. Do primeiro traço derivam as Belas Infiéis, modo de tradução francês clássico, dominante durante os séculos XVII e XVIII; do segundo, mais filológico, provêm as traduções mais "literalizantes fundadas na oralidade e na língua popular". Berman (2012, p. 21) alude nesse caso às obras de Galland, Chateaubriand, Paul-Louis Courier e Armand Robin. Pode-se provavelmente acrescentar à lista os nomes de Meschonnic e do próprio Berman, pois, como aponta Barbara Godard (2001, p. 66), a noção bermaniana de tradução-da-letra seria tributária da concepção de Meschonnic do "ritmo como ética" e da tradução de "ritmo por ritmo, repetição por repetição".

Esse debate se situa numa reflexão mais ampla a respeito da história da tradução na França "pós Amyot". No capítulo final do livro a respeito do assunto, Berman compara essa história com Roma e com a Alemanha nos seguintes termos: “do espaço literário, crítico e filológico da Bildung surge impetuosamente a terceira figura histórica da tradução ocidental, depois da figura translativa nascida em Roma, desenvolvida na Idade Média e conservada pelo mundo anglo-saxão, e a figura tradutiva representada pelas Belas Infiéis" (BERMAN, 2012, p. 236). A função e a visada da tradução para os alemães seria distinta daquela clássica e dominante dos franceses, pois, por um lado, ela surge como um dos modos de constituição de uma cultura 
nacional e, por outro, "longe de ser apropriativa, ela abre radicalmente essa cultura ao Estrangeiro, e ainda restituindo escrupulosamente a figura formal dos originais. Traduzir não é adaptar, adaptar conteúdos, mas reproduzir formas" (p.236).

As consequências que Berman depreende desse entendimento são consideráveis. A mais importante delas talvez seja a de que os alemães teriam tirado a tradução do "espaço retórico e imitativo que era o seu em Roma e no Renascimento, para colocá-lo em outro espaço, da hermenêutica e da filologia" (BERMAN, 2012, p. 237). Berman, em certo sentido, volta à sua prova do estrangeiro ao reiterar logo em seguida:

\footnotetext{
...com Schleiermacher e Schlegel, traduzir muda fundamentalmente de sentido e de lugar. Torna-se um ato crítico: é o criticism by translation de Ezra Pound. Enquanto ato crítico, torna-se essencialmente reflexivo, e não é por acaso se neste período são escritos os primeiros textos de "reflexão" sobre a tradução e até, com Dos diferentes métodos do traduzir de Schleiermacher, o primeiro texto teórico do Ocidente sobre a tradução. [...] Desta "revolução, que muda o lugar da tradução, nós somos os herdeiros. Saber se este novo lugar (o lugar crítico, hermenêutico e filológico) é o lugar último da tradução, é outra história. (BERMAN, 2012, p. 237-238).
}

Berman (2012, p. 239), ainda no capítulo final, retoma o fio de seu argumento da dupla origem da tradução na França para acrescentar que, se há vários tradutores que adotaram, cada qual à sua maneira, algo do modelo hermenêutico-filológico, no século XX, a maioria dessas traduções são fragmentárias, havendo poucas traduções completas. Com efeito, a realidade da tradução na França, nos anos 1980, para Berman (2012, p. 239) "parece esgarçada entre o modelo clássico das Belas Infiéis, o modelo anglo-saxão da translation e o alemão da Übersetzung".

Essas observações permitem situar melhor o trabalho efetuado por ele ao longo dos anos. Arriscamos afirmar que, mais do que definir de modo categórico o que cada língua-cultura adota como modo de traduzir, os três "modelos" serviriam para mapear o modo como foram sendo constituídos espaços tradutórios em grandes áreas linguísticas europeias. Aos modelos tripartites aqui descritos - traditio-translatio-traductio | crítica-comentáriotradução | mutação-comunicação-tradição | translation-traduction- 
Übersetzung - caberia, pois, mais um papel esquemático do que assertivo, ainda que, em sua prática, por vezes, Berman seja seduzido por uma postura um pouco mais prescritiva. Como observa Barbara Godard (2001, p. 71), em Pour une critique des traductions: John Donne, Berman chega a julgar certas traduções do poeta londrino de "perniciosas". Em sua crítica Berman pareceria, para Godard, estar opondo tradução etnocêntrica e tradução ética, tradução hipertextual e tradução poética, de tal modo que assumiria "a forma abstrata e universal com força de lei", como a passagem abaixo poderia indicar:

\footnotetext{
Contudo, se os modos de tradução são sempre culturalmente individualizados, e se daí se depreende que não é possível haver um "modelo universal" de tradução, o traduzir como tal, segue determinado por algo supra-cultural, supra-linguístico, se não supra-histórico. Existe uma Ideia de tradução, uma Ideia no sentido platônico, à qual toda obra-detradução pode se referir. Essa Ideia, como toda verdadeira Ideia, não é nem uma norma, em um conceito, e ela não se encerra em nenhuma definição. Mas é a correspondência a essa Ideia que garante a verdade de uma tradução, para além de qualquer adequação ou inadequação aparentes.

Tradicionalmente, a verdade de uma tradução é significada pela noção de fidelidade: a "verdadeira" tradução é a tradução "fiel". Aí, como em várias outras dimensões da existência humana há correlação absoluta entre verdade e fidelidade.

É possível, como fazia o tradutor Jacques Peletier no século XVI, falar em "lei" de tradução. Essa lei, como toda lei, pode ser transgredida, como atesta o elo não menos profundo que vincula desde suas origens o traduzir à mentira e à traição. (BERMAN, 2012, p. 24)
}

A longa citação acima pareceu-nos necessária por revelar a complexidade de certa dimensão abstrata da concepção bermaniana do traduzir. Com efeito, Berman tensiona os modos de traduzir individualizados, um pouco como Max Weber e seus tipos ideais, com uma Ideia de tradução. Godard (2001, p. 68), via Meschonnic, chama esse tensionamento de "confusão filosófica". Há, sim, deslocamentos, mas eles, a nosso ver, operam mais como uma tensão produtiva do que como suposta “confusão" entre abordagens distintas. À dimensão epistemológica (históricofuncional) acrescenta-se outra metafísica que nos lembra que, não raro, há em 
cada sujeito uma autoconsciência sobre o que seria a "verdadeira" tradução de uma obra. A ênfase em alguns momentos numa "verdade da tradução" (em geral colocada entre parênteses pelo próprio Berman), suplementando a fina observação histórica que tantas vezes realiza, poderia apontar, numa leitura apressada, para uma apropriação descontextualizada de sua "sistemática da deformação". Essa abordagem, tantas vezes retomada em trabalhos de jovens pesquisadores, se não for compreendida em sua historicidade, como um esforço de crítica a uma tendência etnocêntrica dominante na França e informada por uma concepção de letra e de ritmo em situação, podem levar a estranhas simplificações.

\section{Tradução | translação}

Nas páginas acima, destacamos o modo como Berman, num duplo movimento, distingue e articula as noções de translação e tradução. Berman reconhece que a translatio podia significar, em latim, desde o transporte físico de objetos, o deslocamento de pessoas, a transferência de direito ou de jurisdição, a transferência metafórica, o deslocamento de ideias e finalmente a tradução. Ele observa também que esse processo de translatio é ao mesmo tempo topológico e linguístico e que, para boa parte dos autores medievais, a topografia vai da origem helênica do saber, migrando para Roma e chegando às línguas-culturas europeias modernas. Nasce aí a compreensão de que a história do ocidente é uma longa cadeia de translações, sendo esse seu destino. Nessa cadeia de transmissões caberia à "tradução" (ainda não nomeada como tal) "transladar", nesse contexto, a sentencia, ou seja, o sentido dos textos. Situar a tradução dentre essas formas de circulação, compreendendo-a desde o espaço onde se movem as transferências, leva Berman também à generalização de que a tradução ocidental seria "tradicionalizante, translativa e aumentativa". Berman acrescenta, inclusive, que tanto na Idade Média quanto atualmente, a tradução pode ter certo estatuto de translação.

O estudo da obra de Nicole Oresme, chamado por Berman (2012, p. 22) em sua genealogia das filiações como o antepassado (ancêtre) do pai da tradução francesa que é Amyot, permitiu ao crítico, em seu Pour une critique 
des traductions: John Donne, enfatizar que a tradução de uma obra faz parte de um conjunto mais amplo de translações ou de circulações. Nesse momento "tradução" e "translação" ainda convergem e seu processo pode se dar em sentidos opostos: no sentido da comunicação ou no sentido da migração. Essas travessias linguísticas, seguindo sempre a topologia da traditio, configuram-se desse modo como uma espécie de "teoria geral da passagem" que permite a Berman mostrar que cada ato de tradução está posto num envelope de níveis interpretativos, num feixe de obrigações e de liberdades; num espaço de mediações que comporta simultaneamente determinantes conceituais, estéticos e políticos.

A riqueza contida nessa teoria geral da passagem, constituída por meio de uma epistemologia histórico-filológica, é menos potente quando Berman (2012, p. 240) afirma categoricamente que: "os modos de tradução nas áreas não literárias ou mesmo para-literárias, podem ser sem esforço vinculados a um modelo estritamente translativo (de transferência de significados)". Aqui são as categorias arquetípicas depreendidas da comparação entre as etimologias de três grandes línguas europeias que ele mobiliza. Essa leitura é, contudo, uma vez mais contrabalançada por uma consciência histórica. Na sequência, argumenta Berman (2012, p. 241):

\footnotetext{
De fato, no século $X X$, vários modos de traduzir, vindos de distintos espaços culturais e linguísticos, coexistem, se misturam e colidem: o mapa da tradução e o de seus modos são mais vastos e mais complexos do que aqueles do século XVI e mesmo do século XIX.

Dentre esses modos, privilegiamos a translation e a Übersetzung, pois são certamente modos maiores e supra-nacionais; mas há também а Перевод [perevod], a traduzione italiana e até a traduçao (sic) brasileira, cada uma com suas próprias características.
}

\section{Tradução | translação | transcriação}

Um dos exercícios intelectuais aos quais Berman se dedica é o de visitar os dicionários e daí depreender certa arqueologia da palavra tradução. No português do Brasil, segundo o Houaiss à tradução, como no francês, correspondem duas acepções: 1) o ato de traduzir; 2) o seu resultado, a transposição. 
O interessante é que, diferentemente do francês, segundo o Houaiss, temos resumidamente as seguintes acepções para translação: 1. ato, processo ou efeito de transladar; 2. METÁFORA; 3. TRADUÇÃO; 4 . movimento de um sistema no qual todos os seus componentes se deslocam paralelamente; 5. transmissão de direito ou posses de uma pessoa para outra. Guarda-se, no português brasileiro, já de partida, um espectro muito mais amplo de possibilidades de relações entre tradução e translação; cabendo a tradução entre as acepções possíveis de translação.

Note-se ainda que, segundo o Houaiss, as acepções de transladar são primeiramente topológicas, em seguida linguísticas, temporais, jurídicas... A saber: 1. transferir(-se) para outro lugar; 2. transplantar; 3. transpor para outra língua, traduzir; 4. transferir para outra ocasião, adiar; 5. passar a responsabilidade de algo para alguém; 6. (pronominal) mostrar alteração; alterar-se, transformar-se; 7. copiar; 8. passar uma escritura no livro do tabelião; 9. dar sentido metafórico a.

No que estaria pensando Berman quando incluiu na sua lista de modos menores a "traduçao (sic) brasileira"? Estaria ele sugerindo uma articulação entre as definição de tradução e translação em português? Uma possível resposta se encontra na conclusão de $A$ prova do estrangeiro quando Berman (2002[1984], p.321) relaciona linguística e tradução, contexto no qual afirma:

\footnotetext{
a tradução nunca pode constituir um simples ramo da linguística, da filologia, da crítica (como acreditavam os românticos) ou da hermenêutica: ela constitui - quer se trate de filosofia, de religião, de literatura, de poesia, etc. - uma dimensão sui generis; e produtora de um certo saber. Mas essa experiência (e o saber que ela engendra) pode ser, em compensação, esclarecida e em parte transformada por outras experiências, outras práticas, outros saberes. É claro que a linguística, no século 20, pode enriquecer a consciência tradutória; o inverso, aliás, é igualmente verdadeiro. A linguística de um Jakobson interroga os poetas, ela poderia também interrogar os tradutores. É exatamente esse jogo recíproco que propõe, no Brasil, Haroldo de Campos.

As traduções e as reflexões sobre a poesia, a crítica e a tradução de Ezra Pound são aqui de uma importância fundamental e seria interessante confrontar a teoria da crítica-tradução (criticism by translation) com as teorias românticas da tradução-crítica. As reflexões de Pound, como as de
} 
Meschonnic, de PoEsie, de Change, tentam definir o que podem ser, no século 20, uma teoria e uma prática da tradução poética.

Chegamos aqui num ponto importante. Berman (2012, p. 7), em Jacques Amyot, traducteur français. Essai sur les origines de la traduction en France, destaca, inicialmente, que o modelo da tradução francesa encontra-se no mesmo movimento de instauração do modelo da prosa francesa, problematizada por ele. No Brasil, o modelo da tradução parece corresponder de modo mais decisivo à instauração do modelo da poesia. Não por acaso, quando se menciona fora do Brasil o que viria a ser uma abordagem brasileira do traduzir, Haroldo de Campos costuma ser o nome a ser lembrado ${ }^{21}$.

Ainda que a tradução brasileira não seja um foco de grande interesse de Berman, ao mencioná-la na conclusão de dois de seus mais importantes livros, é destacada sua relevância no campo. Não é, pois, de se desconsiderar o lugar que é dado por Berman à dita tradução brasileira: por um lado ele a situa num espaço em que linguística e tradução se interseccionam, na esteira dos trabalhos de Jakobson; por outro, ela é aproximada às reflexões do criticism by translation de Ezra Pound e da tradução-crítica dos românticos alemães. Uma das especificidades da tradução brasileira seria, contudo, o fato de Haroldo de Campos não nomear esse tipo de prática tradutiva de tradução e sim de transcriação.

Se observarmos a definição de tradução encontrada no dicionário Houaiss, vemos que Haroldo de Campos a considera pertinente, pois a Ideia de tradução figurada por Berman parece ecoar ali. O nó é que, ao associar a tradução da forma (isomorfismo, paramorfismo) à transcriação, Haroldo de Campos acaba por vincular a palavra tradução à tradução semântica que, no

\footnotetext{
${ }^{21}$ Há aqui uma referência importante para nós, que é "Situação de Baudelaire", de Paul Valéry. No início de seu texto sobre a importância de Baudelaire para a poesia moderna ele constata que indubitavelmente a projeção deste se deve à tradução de sua obra pelo mundo, assim como a originalidade de sua poesia se deve em grande medida à sua relação, arrisco dizer translacional, com Edgar Poe. Reconhecer essa capacidade de transferir sentidos como um parâmetro para dimensionar o lugar de uma obra e sua projeção é o que o texto de Valéry inspira. Para desdobramentos de uma abordagem de inspiração translacional via Valéry cf. Álvaro Faleiros e Roberto Zular, "Situação de Valéry traduzido no Brasil". Remate de Males, 2018.
} 
esquema de Berman, se aproximaria talvez mais da translatio latina (e à tradução da sententia) ou ainda à translation anglo-americana.

Há, contudo, no Brasil, um outro conjunto de pensadores que, dentro do mesmo modelo-da-tradução/modelo-da-poesia, exploraram de outro modo a relação entre tradução e linguística. Todos eles - José Paulo Paes, Mário Laranjeira e Paulo Henriques Britto -, ainda que de formas distintas, apropriam-se da transposição criativa jakobsoniana. Os três procuram se distanciar da transcriação. Talvez seja possível compreender a abordagem textual ${ }^{22}$ desses pensadores-tradutores como um esforço para produzir uma tradução-comentário mais tradicionalizante e não uma tradução-crítica (transcriação) nos termos modernos aos quais adere Haroldo de Campos. Esses tradutores-comentadores estão interessados em fazer com que a tradução poética, dentro de sua especificidade, é claro, aproxime-se da Ideia de tradução significante, pois todos parecem aderir à concepção de tradução como tradução de uma forma; ainda que esta varie quanto ao lugar dado ao semântico e ao cultural.

A relação de cada um desses pensadores-tradutores com a tradição também varia. Pode-se afirmar que Mário Laranjeira opera mais diretamente na área acadêmica, tendo desenvolvido suas reflexões por meio da significância (via Kristeva, Delas \& Filliolet, Meschonnic e Riffaterre). Por ser pensador da área do francês, também na escolha de seus autores é mais tradicionalizante, trabalhando essencialmente com autores canônicos de suas áreas linguísticas.

As relações de José Paulo Paes e de Haroldo de Campos são bem mais abertas. Ambos poetas, eles traduziram de várias línguas, por vezes de modo indireto, apoiados em conhecimentos rudimentares de línguas distantes ou ainda em parceria com estudiosos desses idiomas. Haroldo de Campos, como vimos, construiu obra bastante sólida, sendo hoje a principal referência quando se fala de uma teoria brasileira do traduzir. Paulo Henriques Britto, o mais jovem dos tradutores-pensadores aqui referidos, se aproxima de Haroldo de Campos e de José Paulo Paes pela importância de sua obra poética e difere dos dois (principalmente de Haroldo de Campos) por

${ }^{22}$ Cf. Álvaro Faleiros. «Approches textuelles pour la traduction du poème au Brésil ». TTR, v.XIX, 2006. 
almejar mais à tradução-comentário do que à tradução-crítica. Seu olhar mais pragmático também se deve ao papel de destaque que ocupa como um dos principais tradutores comerciais de prosa literária do inglês no Brasil.

No presente momento, até onde foi possível averiguar, nenhum desses tradutores-pensadores ou seus comentadores ensaiou compreendêlos a partir das categorias bermanianas que se mostraram, a nosso entender, esclarecedoras das origens do modelo-de-tradução brasileiro. Seu entendimento, creio, pode ganhar consistência se projetarmos as obras traduzidas e as obras sobre tradução desses tradutores-pensadores dentro do que chamaremos doravante de espaço translacional.

Interessa-nos, sobretudo aqui, a "teoria geral da passagem" que, como vimos com Sherry Simon, visa a mostrar que, nos atos de tradução, se entretecem níveis interpretativos, atravessados por condicionantes e liberdades em meio a um espaço múltiplo de mediações, que comporta simultaneamente determinante conceituais, estéticos e políticos. Se olharmos para as múltiplas acepções de translação em português vemos que a tradução ali se insere, juntamente com a metáfora. Se olharmos para transladar, as acepções comportam transportes, transposições, transplantes, traduções, transmutações, transgressões e cópias. Partir da translação permite, pois, pensar a tradução e seu traduzir como pivô de uma constelação de diferentes níveis interpretativos situados ética, poética e politicamente e entender esse campo como um espaço translacional. Nesse sentido, nos é especialmente cara a seguinte compreensão de Berman (1995, p. 17):

\footnotetext{
Cabe ao crítico esclarecer o porquê da falha tradutiva (convergimos aqui, de certa maneira, nossos socio-semio-críticos mas sem seus conceitos e seus tipos de discurso) e também preparar o espaço de jogo de uma retradução, sem "posar de conselheiro". Esse espaço de jogo insere-se num espaço mais vasto, o da translação de uma obra estrangeira numa língua-cultura. Essa translação não provém exclusivamente da tradução. Ela provém também da crítica e de várias formas de transformação textual (e até não textuais) que não são tradutivas. O conjunto constitui a translação de uma obra. Há uma dialética entre as translações não tradutivas e as traduções.
}

A observação de um ato tradutório ou o espaço de jogo de uma retradução parece exigir do crítico a consciência de quais são as instâncias 
implicadas nesse espaço mais vasto. Acreditamos ser, contudo, reducionista imaginar que as relações entre as translações não tradutivas e as traduções dentro do espaço translacional sejam necessariamente dialéticas. Não há síntese entre os pensamentos de Mário Laranjeira, Paulo Henriques Britto e Haroldo de Campos. As tensões permanecem e, a partir delas, vão se instaurando modos de conceber a tradução. Pensar projetos tradutivos e horizontes da tradução passa a ser fundante para o desenvolvimento de analíticas, críticas e comentários envolvendo a tradução, cuja sistemática será compreendida em função da historicidade dos modelos do tradutor, da obra e do crítico.

Quando analisamos em outro estudo ${ }^{23}$ as relações entre Paulo Henriques Britto e Haroldo de Campos, procuramos nuançar suas poéticas do traduzir em função da obra a ser traduzida e dos afetos envolvidos. Não se traduz um clássico como se traduz um contemporâneo, não são as mesmas liberdades que se um tradutor costuma se dar quando se auto-traduz, traduz em função de uma poética própria ou traduz sob encomenda. Podemos dizer que o tradutor-crítico (transcriador) Haroldo de Campos faz-se tradutorcomentador diante de Leopardi e que o tradutor-comentador Paulo Henriques Britto, ao se autotraduzir, opera como um transcriador. $\mathrm{O}$ ato tradutório parece, pois, ser mais bem compreendido se articulado em seu espaço translacional. Nesse contexto, a agência (da ductio) é precisamente o efeito relacional das interações em jogo: seu real alcance deve ser dimensionado numa situação precisa.

Enfim, ao revisitarmos a arqueologia da tradução proposta por Berman, com suas tensões epistemológicas e metafísicas, depreendemos a potência teórica de algumas tríades conceituais. As mais produtivas parecem ser tradição-translação-tradução, traduction-translation-Übersetzung e tradução-crítica-comentário. A partir delas e do duplo funcionamento (linguístico e topológico) da translatio, seria possível esboçar um modelo-detradução brasileiro cujo espaço translacional é atravessado pelo modelo-dapoesia e habitado pela Ideia de uma tensão constante entre tradução e transcriação. Esse modelo, informado pela semiótica jakobsoniana (mas não

23 "A voz e o silêncio em Paulo Henriques Britto e Haroldo de Campos tradutores". Literatura e Sociedade (19), 117-130, 2015. 
só), teria como "pai" Haroldo de Campos; e o caráter transformador e transcriador de sua poética e da ética que acarretam, tensionadas pelas abordagens textuais, exigem permanente historicização. Esta, por sua vez, pressupõe o espaço da (re)retradução como um dos pivôs agentivos do espaço translacional, espaço este que, por ser inconclusivo, pressupõe a tradução sempre em devir.

\section{Bibliografia}

BERMAN, Antoine. El lugar de la traducción. Tradução Beatriz Castillo. Revista Sitio, Buenos Aires, Revista Sitio, p.124-127, 1981.

BERMAN, Antoine. L'épreuve de l'étranger: culture et traduction dans l'Allemagne romantique: Herder, Goethe, Schlegel, Novalis, Humboldt, Schleiermacher, Hölderlin. Paris: Gallimard, 1984.

BERMAN, Antoine. La traduction et la lettre ou l'auberge du lointain, in Les tours de Babel. Mauvezin: Trans-Europ-Repress, 1985; 2a ed. Paris: Le Seuil, 1999.

BERMAN, Antoine. Critique, commentaire et traduction (Quelques réflexions à partir de Benjamin et de Blanchot). Po\&sie, n. 37, Paris, Librairie Classique Eugène Belin, p. 88-106, 1986.

BERMAN, Antoine. Tradition-Translation-Traduction, Po\&sie, n. 47, Paris, Librairie Classique Eugène Belin, p. 85-98, 1988a.

BERMAN, Antoine. De la translation à la traduction / Da translação à tradução. Tradução de Marie Hélène C. Torres, Marlova Aseff. Scientia Traductionis, n. 9, p. 71-100, 2011[1988].

BERMAN, Antoine. A tradução e seus discursos. Tradução de Marlova Aseff. In: Alea: Estudos Neolatinos. V.11, n. 2, julho-dezembro. Rio de Janeiro: 7Letras, p. 341-353, 2009[1989].

BERMAN, Antoine. Pour une critique des traductions: John Donne. Paris: Gallimard, 1995. 
BERMAN, Antoine. L'Age de la traduction - "La Tâche du traducteur" de Walter Benjamin, un commentaire. Paris, Presses Universitaires de Vincennes, coll. "intempestives" 2008.

BERMAN, Antoine. Translatio studii et pouvoir royal, Po\&sie, n 80, p. 190200, 1997.

BERMAN, Antoine. Jacques Amyot, traducteur français. Essai sur les origines de la traduction en France. Paris: Belin, 2012.

BRUNI, Leonardo. Da tradução correta. Tradução de Rafael Carmolinga. In: FURLAN, M. (org.). Clássicos da teoria da tradução - Renascimento. Florianópolis: USFC/NUPLITT, 2006, p. 52-83.

CASSIN, Barbara (dir.), Vocabulaire européen des philosophies: dictionnaire des intraduisibles. Paris: Le Seuil/Le Robert, 2004.

KINNUNEN, Tuija; KOSKINEN, Kaisa. Introduction. In: (eds.). Translators' Agency. Tampere: Tampere University Press, 2010, p. 4-10.

GODARD, Barbara. L'Éthique du traduire: Antoine Berman et le "virage éthique" en traduction. TTR, 14 (2), p. 49-82, 2001.

LUSIGNAN, Serge. Parler vulgairement. Paris/Montréal: Vrin/Presses de l'Université de Montréal, 1986.

PETRY, Simone. Antoine Berman, leitor do Romantismo alemão. Scientia Traductionis, n.11, p. 368-376, 2012. Disponível em http://dx.doi.org/10.5007/1980-4237.2012n11p368). Acesso em 15 jan. 2021.

SERRES, Michel. La traduction. Paris: Éd. de Minuit, 1974.

SIMON, Sherry. Antoine Berman ou l'absolu critique. TTR, 14 (2), p. 19-29, 2001.

\section{Resumo}

Antoine Berman, um dos expoentes dos estudos da tradução do século XX, colocou como uma das primeiras tarefas para o campo a escrita de uma história da tradução. Nesse sentido, um de seus primeiros objetivos foi fazer uma arqueologia da palavra traductio comparando-a com outros termos afins (translatio e traditio), assim como com sua etimologia em francês, inglês e 
alemão. O intuito deste artigo é apresentar reflexão a partir desses usos e apontar para possíveis desdobramentos dessa história para se pensar as possíveis relações entre translação e tradução no Brasil

Palavras-chave: Antoine Berman; Traductio; Translatio; Transcriação; Haroldo de Campos.

\begin{abstract}
Antoine Berman, one of the exponents of translation studies in the 20th century, describes translation history as one of the first tasks for the field. One of his first tasks was to make an archeology of the word traductio comparing it with other related terms (translatio and traditio), as well as with its etymology in French, English and German. The purpose of this article is to present a reflection based on these uses and to point to possible developments of this history in order to think about the possible relations between translatio and translation in Brazil.
\end{abstract}

Keywords: Antoine Berman; Traductio; Translatio; Transcreation; Haroldo de Campos. 